\title{
Potential Glass Network for IR Applications and Rare-Earth Ions
}

\author{
İ. $\mathrm{KABALCI}^{a, *}, \mathrm{H} . \mathrm{GÖKÇE}{ }^{b}$ AND N.Ö. KÖRPE ${ }^{c}$ \\ ${ }^{a}$ Department of Electric-Electronic Engineering, Engineering Faculty, \\ Uşak University, 64100 Uşak, Turkey \\ ${ }^{b}$ Prof. Dr. Adnan Tekin Materials Science and Manufacturing Technology Application \\ and Research Center, Istanbul Technical University, 34469 Maslak, İstanbul, Turkey \\ ${ }^{c}$ Department of Materials Science Engineering, Engineering Faculty, \\ Eskisehir Osmangazi University, 26480 Eskişehir, Turkey
}

Received: 23.05.2021 \& Accepted: 04.10.2021

Doi: 10.12693/APhysPolA.140.222 *e-mail: idris.kabalci@usak.edu.tr

\begin{abstract}
By conventional melt-quenching, we have prepared novel optical amorphous borate-based glass sample series of $\mathrm{B}_{2} \mathrm{O}_{3}-\mathrm{ZnO}-\mathrm{TiO}_{2}$ host materials to investigate their optical properties and microstructure. Following the successful preparation, the density $\rho$ and molar volume $V_{m}$ of the samples were calculated by the Archimedes principle. In addition, microstructural and optical properties of the materials were determined by the experimental techniques, such as the Fourier transform infrared, Raman, X-ray diffraction, scanning electron microscopy, and UV-vis absorption techniques. The microstructure of the prepared borate-based optical glass materials shows two crystalline phases for various glass compositions, such as titanium oxide $\mathrm{TiO}_{2}$, and zinc borate $\mathrm{Zn}_{3}\left(\mathrm{BO}_{3}\right)_{2}$. Finally, the direct energy band gaps were $3.5,3.55$, and $3.6 \mathrm{eV}$ for the $x \mathrm{ZnO}$ contents $(x=45,50$, and $55 \mathrm{~mol} \%)$, respectively.
\end{abstract}

topics: borate glasses, chemical properties, crystalline structure

\section{Introduction}

With quite a lot of different applications, borate $\left(\mathrm{B}_{2} \mathrm{O}_{3}\right)$-based optical glass materials have attracted the attention of many researchers and famous commercial companies. Appropriate $\mathrm{B}_{2} \mathrm{O}_{3}$-based optical glasses which are most suitable as host materials have been investigated over the last years and related papers have been published [1-5] due to the variety of their industrial applications, such as transparent dielectric layer [6], bulk lasers, optical fibers, waveguide lasers and optical amplifiers $[7,8]$. Borate-based glasses might exhibit different interesting optical, thermal, and mechanical properties when compared with silicate $\left(\mathrm{SiO}_{2}\right)$, phosphate $\left(\mathrm{P}_{2} \mathrm{O}_{5}\right)$, tellurite $\left(\mathrm{TeO}_{2}\right)$ and fluorite glass materials [9-11]. Borate-based glass materials - when compared to tellurite glasses - have two important extra properties, namely, high transparency and mechanical stability, therefore they are highly desirable in various applications. Boratebased glass materials can be produced over a large compositional range with high transparency in both the visible (vis) and near-infrared regions (NIR) (300-6000 nm) [12].

In addition, borate-based glasses show more chemical and mechanical stabilities in threedimensional random networks with triangular $\mathrm{BO}_{3}$ and tetrahedral $\mathrm{BO}_{4}$ stretching modes [7, 8]. Moreover, $\mathrm{B}_{2} \mathrm{O}_{3}$-based optical glass samples also have an easy glass forming tendency due to the $\mathrm{B}^{3+}$ combination with oxygen sides in a glass network [13]. As in the glass network, the addition of $\mathrm{ZnO}$ increases the ionic properties, refractive index [14], and decreases the melting temperatures [15]. A previous study reported that a $\mathrm{ZnO}$ addition increased the transmission window of glass samples [14]. Masai et al. explored $\mathrm{ZnO}$-based glass materials and ceramics with high transparency, high dielectric conductivity [16], and high refractive index properties [17].

It has been known that the addition of transitionmetal oxides as a dopant to the $\mathrm{B}_{2} \mathrm{O}_{3}$-based glasses might change their chemical and physical properties, such as ionic conductivity, refractive index, transparency, and stability [18]. For instance, Prasad et al. stressed that the incorporation of titanium oxide $\left(\mathrm{TiO}_{2}\right)$ to the glass matrix [2] not only improves its chemical durability but also increases its nonlinear refractive index [19, 20]. Therefore, $\mathrm{TiO}_{2}: \mathrm{B}_{2} \mathrm{O}_{3}$-based glasses might be very promising candidates to be used as nonlinear optical devices [21-23]. Depending upon glass concentration, the heavy-metal oxide may take a role either as a glass network modifier or as a network former. 
Borate-based optical glass materials also have other important applications in decorative and exterior fields due to their mechanical and thermal stability, as well as transmission window properties. Moreover, borate-based glass materials have applications in electronic and optical communication fields since they are a suitable good host material as a laser glass former for rare-earth elements, such as $\mathrm{Eu}^{3+}, \mathrm{Tb}^{3+}, \mathrm{Er}^{3+}, \mathrm{Er}^{3+} / \mathrm{Yb}^{3+}$, $\mathrm{Yb}^{3+}[24-32]$. However, when faced with other oxidized glass materials, such as $\mathrm{TeO}_{2}$, the higher melting temperature and the refractive index might be considered a disadvantage in industrial production. At present, $\mathrm{Nd}^{3+}$ (purple glass), $\mathrm{Er}^{3+}$ (light purple glass), and $\mathrm{Yb}^{3+}$ (colorless glass) are among the most commonly used rare-earth elements for solidstate lasers [33].

In this research, microstructural and optical properties of the ternary novel glass series of $\mathrm{B}_{2} \mathrm{O}_{3}-\mathrm{ZnO}-\mathrm{TiO}_{2}$ host materials have been characterized by using systematic experimental methods, such as the Fourier transform infrared (FTIR), Raman, X-ray diffraction (XRD), scanning electron microscopy (SEM), and UV-vis absorption techniques. Investigations of $x \mathrm{ZnO}$ various glass compositions $(x=45,50$, and $55 \mathrm{~mol} \%)$ on their microscopic and optical parameters give rise to clarification, and exploration of rare-earth ions (REI) for future researchers, and electronic applications.

\section{Experimental work}

Optical laser glass samples, $(95-x) \mathrm{B}_{2} \mathrm{O}_{3}-x \mathrm{ZnO}-$ $5 \mathrm{TiO}_{2}$, planned for this study were prepared by the best-known conventional melt-quenching method for various glass compositions $x=45,50$, and $55 \mathrm{~mol} \%$. The reactive grades of all chemical components used in experimental production consist of $\mathrm{B}_{2} \mathrm{O}_{3}$ (99.8\% purity, Sigma-Aldrich), $\mathrm{ZnO}$ (99.9\% purity, Sigma-Aldrich) and $\mathrm{TiO}_{2}$ (99-100\% purity, Sigma-Aldrich) commercial high purity powders. Batches of $5 \mathrm{~g}$ in size were mixed and melted for $1 \mathrm{~h}$ using a platinum crucible with a closed lid in an electrically heated ash furnace at $1200{ }^{\circ} \mathrm{C}$ for all homogeneous glass samples. The high-melting glasses were then cast onto a stainless-steel plate and pressed with another stainless-steel plate at room temperature to quench. The same glass compositions doped with $\mathrm{Yb}^{3+}$, prepared by the conventional method, were investigated in [34]. All optical glass samples obtained were annealed at $300^{\circ} \mathrm{C}$ for $24 \mathrm{~h}$. Glass materials examined with different glass compositions $(95-x) \mathrm{B}_{2} \mathrm{O}_{3}-x \mathrm{ZnO}-5 \mathrm{TiO}_{2}$ are hereinafter referred to as BZT2, BZT5, and BZT3 for $\mathrm{ZnO}(x=45,50$, and $55 \mathrm{~mol} \%)$.

The density of each glass sample was measured in a precise step using the Archimedes principle, with distilled water as the dipping liquid. For experimental characterization purposes, FTIR spectra were recorded with a Perkin Elmer FTIR Spectrometer in the range of $1200-400 \mathrm{~cm}^{-1}$. The microstructure of the prepared tellurite optical glasses was measured with an FT-Raman spectrophotometer (Digilab FTS 7000 Series) in the range $0-1200 \mathrm{~cm}^{-1}$. Digital density data were recorded at $1 \mathrm{~cm}^{-1}$ intervals. To determine the Raman spectrum, an Nd:YAG laser system operating at $1064 \mathrm{~nm}$ was used as the excitation source, and the sample was excited with a power level of about $500 \mathrm{~mW}$. The scattered radiation was detected by cooling the Ge detector with a spectral resolution of $8 \mathrm{~cm}^{-1}$.

The XRD technique, as a common well-known technique, was performed on both powdered as-cast glasses, and annealed glass samples using a Rigaku XRD, Ultimate III, to investigate the glass structure and identify the crystallized phases. All traces were recorded using $\mathrm{Cu} K_{\alpha}$ radiation, and the diffractometer setting in the $2 \theta$ range from 10 to $90^{\circ}$ by changing the $2 \theta$ with a step size of $0.02^{\circ}$. All of the glass samples were ground to fine powders, and Eva Software (Bruker) was used to label peaks, and then distinguish the crystalline phases existing in the sample. After obtaining the glasses, the International Center for Diffraction Data (ICD) files were used to identify the crystallized phases by comparing the intensities, and the peak positions. The absorption spectra for the well-polished glass samples were recorded with a UV-3150 Shimadzu UV-visNIR spectrophotometer in the $400-800 \mathrm{~nm}$ wavelength range to calculate the optical energy band gap by using the Lambert-Beer law.

The scanning electron microscopy was carried out both in a ZEISS EVO'50 and equipped with the energy dispersive spectrometer attachment Bruker EDAX. The SEM technique was used to investigate the microcrystallization processes, and to determine the crystallization mechanism both on the surface and the cross-sections of the glass samples.

\section{Results and discussion}

In this research, the conventional melt-quenching method was used for the preparation of optical glasses with various glass compositions, such as $x=45,50$, and $55 \mathrm{~mol} \%\left(\mathrm{~B}_{2} \mathrm{O}_{3}-x \mathrm{ZnO}-5 \mathrm{TiO}_{2}\right)$. All the glass samples were transparent, colorless, homogeneous, and non-fragile at room temperature. We calculated the density of the glass samples that increase with increasing the glass composition due to the heavier Zn-atomic mass in the glass network as shown in Fig. 1. As $x$ varied from 45 to $55 \mathrm{~mol} \%$, the measured density of the glass samples increased from $3.95,4.75$, to $5.27 \mathrm{~g} / \mathrm{cm}^{3}$. Moreover, the molar volume $V_{m}$ of the glass samples $\left[\mathrm{cm}^{3}\right]$ was calculated according to [35], i.e.,

$$
V_{m}=\frac{M_{\text {glass }}}{\rho_{\text {glass }}}
$$

where

$$
M_{\text {glass }}=\frac{(95-x) M_{\mathrm{TeO}_{2}}+x M_{\mathrm{ZnO}}+5 M_{\mathrm{TiO}_{2}}}{100},
$$




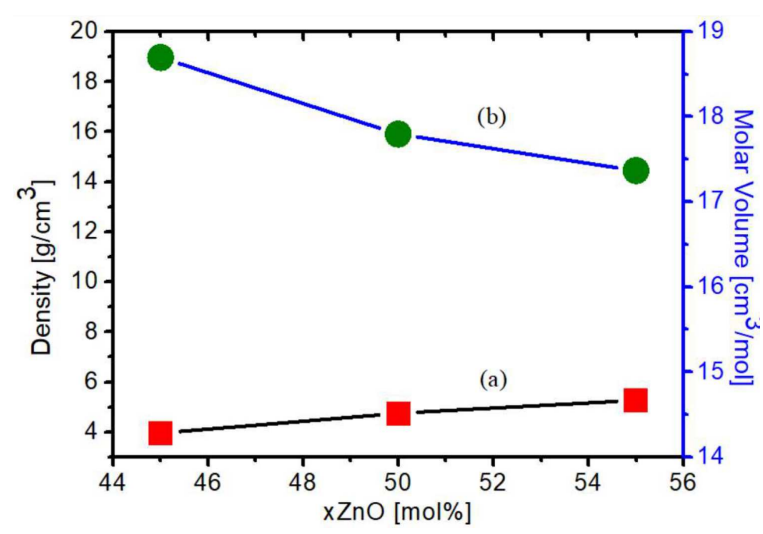

Fig. 1. (a) Density and (b) molar volume of the glass samples.

where $M_{\text {glass }}$ and $\rho_{\text {glass }}$ are the mass and density of the glass samples, respectively. As seen in Fig. 1, molar volume $\left(V_{m}=18.97,15.90\right.$, and $\left.14.44 \mathrm{~g} / \mathrm{mol}\right)$ decreases when the density $\left(\rho_{\text {glass }}=3.95,4.75\right.$, $5.27 \mathrm{~g} / \mathrm{cm}^{3}$ ) of the samples increases. Naga Raju et al. stressed that the decrease in molar volume could be related to the densities of glass materials due to the contraction of the glass network [16]. For the $50 \mathrm{~B}_{2} \mathrm{O}_{3}+15 \mathrm{Na}_{2} \mathrm{O}+15 \mathrm{ZnO}+(20-x) \mathrm{CaO}+$ $x \mathrm{Bi}_{2} \mathrm{O}_{3}$ glass network, Abouhasva and Kavas determined the density and molar volume as a function of $\mathrm{Bi}_{2} \mathrm{O}_{3}$ glass compositions that affect the glass structures by filling the interstitial spaces by higher density, and molecular weight [36].

The FTIR spectra were measured for both the powdered glass materials, and annealed at around 792,767 , and $792{ }^{\circ} \mathrm{C}$ temperature for the BZT2, BTZ5, and BZT3 samples shown in Figs. 2 and 3, respectively. Here, in order to examine the structural changes of glass materials obtained for FTIR more clearly, heat treatment was carried out according to differential thermal analysis (DTA) onset temperature changes. The FTIR spectra show three main absorption regions, namely from 561 to $758 \mathrm{~cm}^{-1}$ which was explained as the deformation modes of the $\mathrm{B}-\mathrm{O}-\mathrm{B}$ linkage bending $[37,38], 791-1083 \mathrm{~cm}^{-1}$ which was assigned as the stretching vibrations of both tetragonal $\mathrm{BO}_{4}$, and $1156-1516 \mathrm{~cm}^{-1}$ which was assigned as the triangular $\mathrm{BO}_{3}$ borate units [39]. However, Gaafar et al. stressed that there are four distinct frequency regions between 140 and $1600 \mathrm{~cm}^{-1}$ in the glass system $(1-x)\left(29 \mathrm{Na}_{2} \mathrm{O}-4 \mathrm{Al}_{2} \mathrm{O}_{3}-67 \mathrm{~B}_{2} \mathrm{O}_{3}\right)-x \mathrm{ZnO}$ [40]. In addition to the FTIR spectra of the glass structures, the annealed optical glass samples at $792^{\circ} \mathrm{C}$ with $10^{\circ} \mathrm{C} /$ min heating rate, as seen in Fig. 3, show the FTIR absorption spectrum peaks. In Fig. 3, IR absorption peaks labeled in detail as 565, 673, $716 \mathrm{~cm}^{-1}$ resulted from $\mathrm{B}-\mathrm{O}-\mathrm{B}$ bending vibrations. The peaks labeled as $813,862,903,986$, and $1064 \mathrm{~cm}^{-1}$ resulted from B-O symmetric stretching vibrations of $\mathrm{BO}_{4}$ units. Further, the peaks labeled as 1234,1302 , and $1360 \mathrm{~cm}^{-1}$ resulted from $\mathrm{B}-\mathrm{O}$

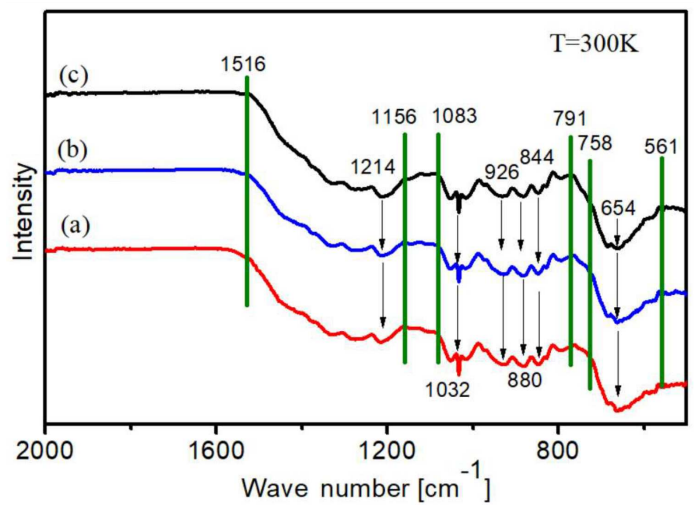

Fig. 2. FTIR spectra for the glass samples: (a) BZT2, (b) BZT5, and (c) BZT3.

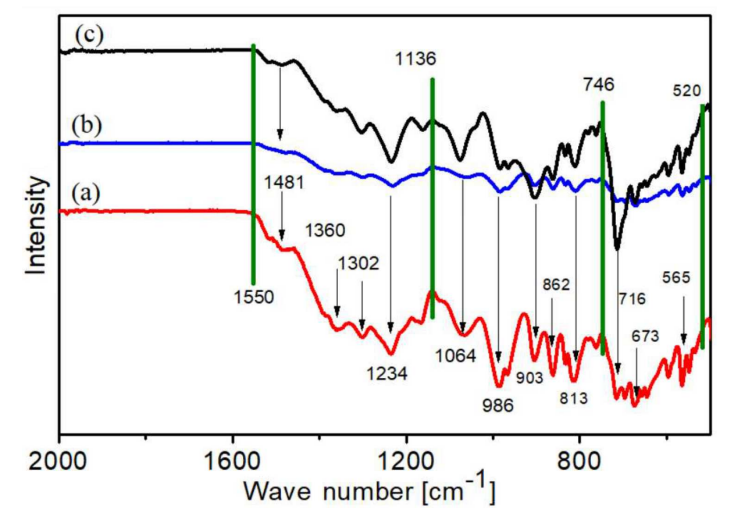

Fig. 3. FTIR spectra for the samples: (a) BZT2, (b) BZT5, and (c) BZT3 annealed at 792, 767, and $792{ }^{\circ} \mathrm{C}$ temperature, respectively.

stretching vibrations of trigonal $\mathrm{BO}_{3}$ units, and $1481 \mathrm{~cm}^{-1}$ resulted from the asymmetric stretching relaxation in trigonal $\mathrm{BO}_{3}$ groups [41, 42].

Here, for the basic structural units of boronbased optical glasses, the glassy structure of $\mathrm{B}_{2} \mathrm{O}_{3}$ determined by Zachariasen is stated to be a 3-dimensional network [24]. Whenever a glass modifier, such as $\mathrm{ZnO}$ and $\mathrm{Na}_{2} \mathrm{O}$, is added to the $\mathrm{B}_{2} \mathrm{O}_{3}$ structure, the triangular $\mathrm{BO}_{3}$ structural units transform into the tetragonal $\mathrm{BO}_{4}$ structural network unit [24].

Moreover, for the binary zinc borate glass materials, the effect of the $\mathrm{ZnO}$ glass ratios on the FTIR absorption spectra includes different regions due to the structural deformation, such as 654,844 , 880,926 , and $1214 \mathrm{~cm}^{-1}$. The absorption band at $654 \mathrm{~cm}^{-1}$ may be assigned as the vibration of the Zn metal cations in their oxygen bonding [35], and the band 844 and $888 \mathrm{~cm}^{-1}$ might be attributed to the vibration of natural bond orbital (NBO) of $\mathrm{BO}_{4}$ groups, and the other band of spectrum 926 may represent $\mathrm{B}-\mathrm{O}$ groups. In addition, the band of absorption spectrum at $1214 \mathrm{~cm}^{-1}$ was attributed to the $\mathrm{B}-\mathrm{O}$ stretching vibrations of $\mathrm{BO}_{3}$ units for the borate sites [35]. 


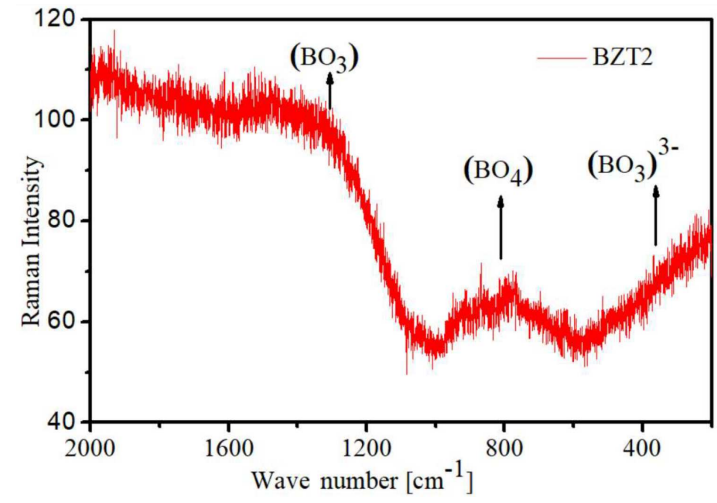

Fig. 4. Raman spectrum for the sample BZT2 at room temperature.

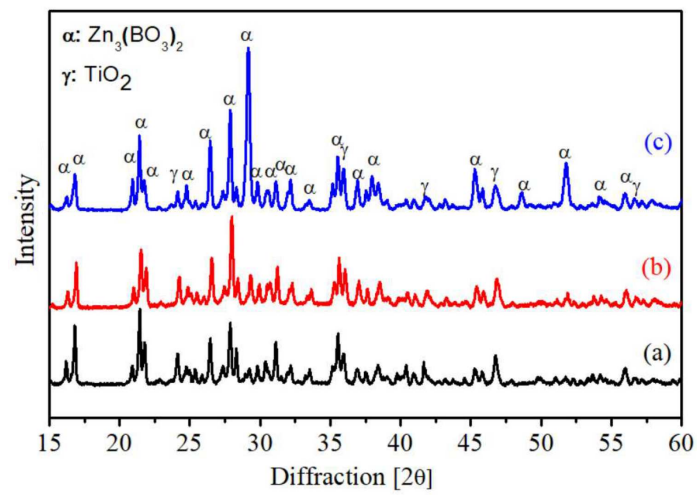

Fig. 5. XRD diffraction patterns for (a) BZT2 annealed at $792^{\circ} \mathrm{C}$, (b) BZT5 annealed at $767^{\circ} \mathrm{C}$, and (c) BZT3 annealed at $792{ }^{\circ} \mathrm{C}$.

As seen in Fig. 4, the Raman spectrum consists of three regions between 200 and $600 \mathrm{~cm}^{-1}$, 600-1000 $\mathrm{cm}^{-1}$, and $1000-1400 \mathrm{~cm}^{-1}$, as triangular $\left(\mathrm{BO}_{3}\right)^{3-}$, tetrahedral $\mathrm{BO}_{4}$, and asymmetric stretching $\mathrm{BO}_{3}$ units which might be comparable with crystalline phases for the obtained glass samples. The Raman spectrum is generally closely related to the bonding between the atoms that make up the structure, due to the vibrational energies of the atoms in this structure. For this reason, the Raman spectrum of borate optical glass structures occurs at different intensities due to the symmetric and asymmetric vibration situations between the $\mathrm{B}$ and $\mathrm{O}$ atoms that make up the structure. Until now, no original research on BZT has been encountered in the literature, but the Raman bands related to tetrahedral $\mathrm{BO}_{4}$, and asymmetric stretching $\mathrm{BO}_{3}$ have been determined in articles on other different components of boron-based optical glass materials [42, 43].

Figure 5 shows the XRD pattern for various glass compositions $x=45,50$, and $55 \mathrm{~mol} \% \mathrm{ZnO}$ which were annealed according to the DTA plot in which the crystalline structure was affected by glass compositions. The BZT2 glass sample was annealed at $792^{\circ} \mathrm{C}$, the BZT5 sample - at $767^{\circ} \mathrm{C}$, and the BZT3 sample - at $792^{\circ} \mathrm{C}$ for $60 \mathrm{~min}$, respectively.
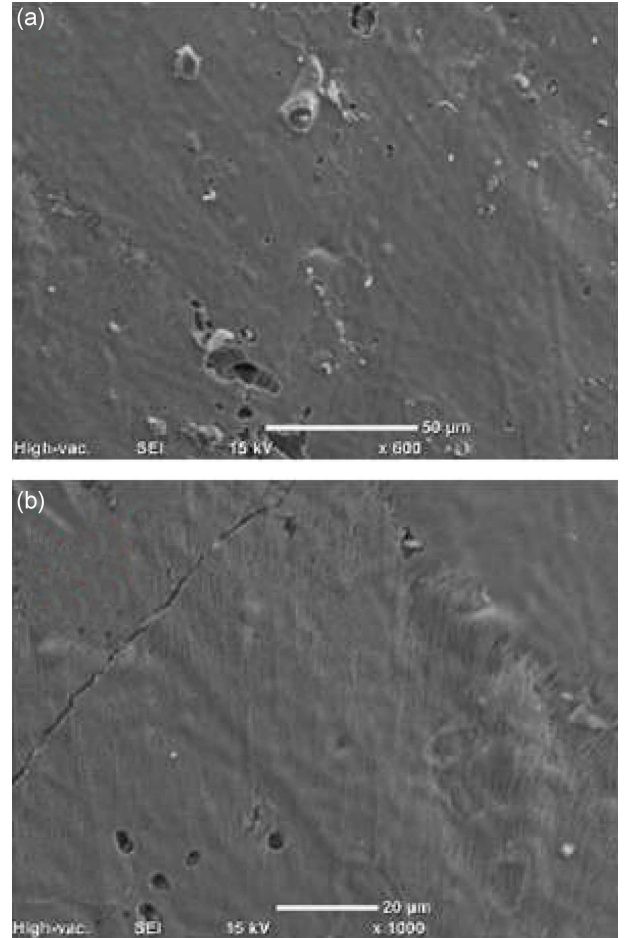

Fig. 6. SEM micrographs from the surface of the annealed samples without etching for the BZT2 in: (a) $50 \mu \mathrm{m}$, and (b) $20 \mu \mathrm{m}$ size.

All the annealed samples were pulverized to be able to get the XRD powder pattern. As seen in Fig. 5, the XRD pattern has two crystalline phases, such as $\mathrm{Zn}_{3}\left(\mathrm{BO}_{3}\right)_{2}$, and $\mathrm{TiO}_{2}$ structural units which are determined by considering the JCPDS 74-1099, and JCPDS file No. 71-5576, respectively.

In addition to XRD, and FTIR spectroscopic analysis, the spectrum of the absorption edge in the UV-vis region has been considered as a useful method to investigate the optical transition $T \%$ and optical energy band gap $E_{g}$ in crystalline and noncrystalline materials. Two kinds of optical transitions are direct and indirect transitions that can occur at the fundamental absorption band edge of crystalline and non-crystalline materials $[25,26]$. Furthermore, surface morphology of the annealed samples was examined under the SEM measurement to be able to determine the micrographs of the surface without any etching procedure. The scanning electron microscopy shows topological differences between the 50 and $20 \mu \mathrm{m}$ size as seen in Fig. 6 . As seen in Fig. 6a and b, SEM pictures show the porosity and cracks of the surface. Although the surface is seen better as smooth in Fig. 6a, possible crystal distributions become evident in a slightly rod-like structure in Fig. 6b.

As mentioned by Rayappan et al., according to the Tauc, Davis, and Mott theory, whenever an atom or molecule is irradiated by an induced photon, an electron in the ground state rises to the excited state because of interaction with 


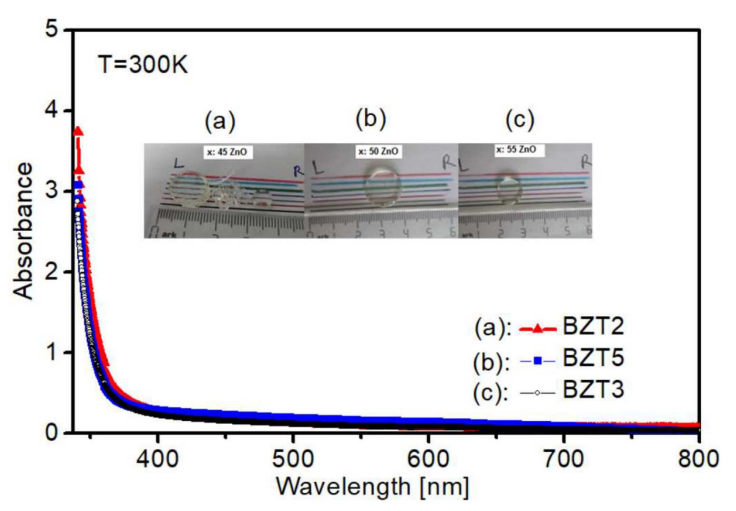

Fig. 7. Optical absorption spectra of: (a) BZT2, (b) BZT5, and (c) BZT3 glass samples.

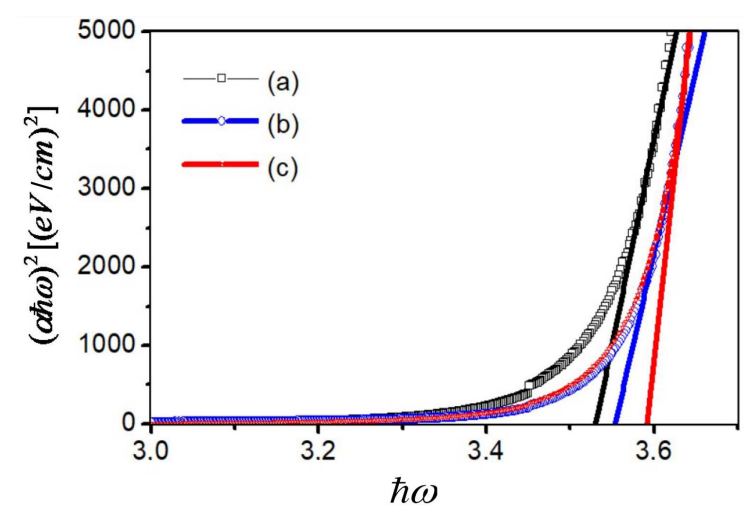

Fig. 8. Optical energy band gaps of: (a) BZT2, (b) BZT5, and (c) BZT3 glass samples.

the induced photon, and thus absorption occurs. At this point, the Mott and Davis theory defines these related transitions as the direct or indirect transition, considering that the induced photon absorbed either the lattice or the electrons in the valence state of the atom [3]. Absorption spectra of the prepared borate-based optical glass samples measured in the wavelength range of 300-800 nm at room temperature are shown in Fig. 7. The effect of the $\mathrm{ZnO}$ content on the optical energy band gap of the glass samples was calculated from the UV-vis absorption spectra. The absorption coefficient $\alpha(\omega)$ is given by [44],

$$
\alpha(\omega)=\frac{\log \left(I_{0} / I\right)}{l},
$$

where $l$ is the thickness of the sample $[\mathrm{cm}]$.

The absorption coefficient $\alpha(\omega)$ at the fundamental edge in terms of the theory given by Davis and Mott [45] for direct and indirect transitions can be written in the following form

$$
\alpha(\omega)=\frac{C}{\hbar \omega}\left(\hbar \omega-E_{\mathrm{opt}}\right)^{n},
$$

where $C$ is the constant and $E_{\mathrm{g}}$ is the energy gap. The direct and indirect optical energy band gap allowed transition is described for $n=1 / 2$ and $n=2$, respectively. Thus, the optical energy band gaps of the glasses were determined by extrapolating the linear region of the curves, obtained by plotting $(\alpha \hbar \omega)^{1 / 2}$ in $\left[(\mathrm{eV} / \mathrm{cm})^{1 / 2}\right]$ units versus $\hbar \omega[\mathrm{eV}]$, to $(\alpha \hbar \omega)^{1 / 2}=0$.

For example, when we compare the direct optical energy band gap values for the preparation, which are highly transparent (as seen in Fig. 7) $\mathrm{B}_{2} \mathrm{O}_{3}$ $\mathrm{ZnO}-\mathrm{TiO}_{2}$ glasses with $\mathrm{TeO}_{2}-\mathrm{B}_{2} \mathrm{O}_{3}-\mathrm{ZnO}$ glasses, in both cases the values gradually increased with the increase of glass modifiers [29]. As seen in Fig. 8, direct optical energy band gaps increase as 3.5, 3.55, and $3.6 \mathrm{eV}$ for 45,50 , and $55 \mathrm{~mol} \% \mathrm{ZnO}$ glass compositions, respectively. It is determined that the electronic structure is directly affected by the optical absorption spectrum of the material, and as $\mathrm{ZnO}$ increases, the absorption spectrum band edge shifts to the longer wavelength, and the optical energy band gap also increases. Sing et al. calculated that the optical energy band gaps of the $\mathrm{B}_{2} \mathrm{O}_{3}-\mathrm{ZnO}-$ $\mathrm{Bi}_{2} \mathrm{O}_{3}$ material also showed similar properties, and emphasized that it was related to different structural changes [46].

\section{Conclusions}

By melt-quenching we have prepared novel compositions based on $(95-x) \mathrm{B}_{2} \mathrm{O}_{3}-x \mathrm{ZnO}-5 \mathrm{TiO}_{2}$ glass network and their structural and optical properties were examined. As $x$ varied from $45-55$ mol.\%, the density of the glass samples showed dependence on the glass compositions (increased from 3.95 to $\left.5.27 \mathrm{~g} / \mathrm{cm}^{3}\right)$. The glass structure showed that the crystalline phases were affected by the increasing $\mathrm{ZnO}$ compositions. The FTIR spectra proved that the increase of $\mathrm{B}$ stretching modes can be related to the increase of $\mathrm{ZnO}$ contents in the glass network. The determined optical energy band gaps showed the increment of $E_{\mathrm{g}}$ due to the glass network promotion of $\mathrm{BO}$ formation within glass structures. The crystalline phases of the heat treated glass samples were determined as $\mathrm{Zn}_{3}\left(\mathrm{BO}_{3}\right)_{2}$, and $\mathrm{TiO}_{2}$.

\section{Acknowledgments}

I.K. would like to express his sincere appreciation to the BAP Commission and its members which supported the project "Number-BAP-15/1-DS-40" in Karabuk University, Karabuk, Turkey.

\section{References}

[1] Y.N.Ch. Ravi Babu, P. Sree Ram Naik, K. Vijaya Kumar, S.V.G.V.A. Prasad, A. Suresh Kumar, Physica B 407, 705 (2012).

[2] N.C.A. de Sousa, M.T. de Araujo, C. Jacinto, M.V.D. Vermelho, N.O. Dantas, C.C. Santos, I. Guedes, J. Solid State Chem. 184, 3062 (2011).

[3] N. Sdiri, H. Elhouichet, C. Barthou, M. Ferid, J. Mol. Struct. 1010, 85 (2012). 
[4] S.M. Lee, Y.H. Jo, H.E. Kim, B.C. Mohanty, Y.S. Cho, J. Am. Ceram. Soc. 95, 1356 (2012).

[5] N.M. Bobkova, E.E. Trusova, Glass Ceram. 68, 349 (2012).

[6] R.A. Elsad, Ahmed M. Abdel-Aziz, Emad M. Ahmed, Y.S. Rammah, F.I. ElAgawany, M.S. Shams, J. Mater. Res. Technol. 13, 1363 (2021).

[7] A.U. Ahmad, Sule Lamido Univ. J. Sci. Technol. (SLUJST) 2, 96 (2021).

[8] Rupesh A. Talewar, Sk. Mahamuda, K. Swapna, M. Venkateswarlu, A.S. Rao, Mater. Res. Bull. 136, 111144 (2021).

[9] R. Balda, J. Fernandez, S. Garcia-Revilla, J.M. Fernandez-Navarro, Opt. Express 15, 6750 (2007).

[10] I. Kabalci, H. Gokce, Acta Phys. Pol. A 125, 877 (2014).

[11] R.A.H. El-Mallawany, Tellurite Glasses, Handbook, CRC Press, Boca Raton (FL) 2002, p. 8.

[12] R. Ciceo-Lucacel, I. Ardelean, J. NonCryst. Solids 353, 2020 (2007).

[13] J.M. Park, H.J. Kim, P. Limsuwan, J. Kaewkhao, Proced. Eng. 32, 855 (2012).

[14] M. Abdel-Baki, F. El-Diasty, J. Solid State Chem. 184, 2762 (2011).

[15] T. Inoue, T. Honma, V. Dimitrov, T. Komatsu, J. Solid State Chem. 183, 2078 (2010).

[16] P. Naresh, G.N. Raju, M.S. Reddy, T.V. Rao, I.V. Kityk, N. Veeraiah, J. Mater. Sci. Mater. Electron. 25, 4902 (2014).

[17] H. Masai, T. Ueno, Y. Takahashi, T. Fujiwara, Opt. Mater. 33, 1980 (2011).

[18] P.S. Prasad, M.S. Reddy, V.R. Kumar, N. Veeraiah, Philos. Mag. 87, 5763 (2002).

[19] N.C.A. de Souse, M.T. de Araujo, C. Jacinto, M.V.D. Vermelho, N.O. Dantas, C.C. Santor, I. Guedes, J. Solid State Chem. 184, 3062 (2011).

[20] L.L. Bragina, O.V. Savvova, Glass Ceram. 66, 7 (2009).

[21] M. Sheikbahae, D.C. Hutchings, D.J. Hagan, E.W. Vanstryland, IEEE J. Quant. Electron. 27, 1296 (1991).

[22] Y. Watanabe, M. Ohnishi, T. Tsuchiya, Appl. Phys. Lett. 66, 3431 (1995).

[23] Y.B. Saddeek, M.S. Gaafar, N.S. Abd ElAal, L. Abd El-Latif, Acta Phys. Pol. A 116, 211 (2009).

[24] A.C. Wright, Int. J. Appl. Glass Sci. 6 , 45 (2015).
[25] A. Ivankov, W. Bauhofer, Phys. Status Solidi A 185, 145 (2001).

[26] G. Lakshminarayana, S. Buddhudu, Mater. Chem. Phys. 102, 181 (2007).

[27] I. Arul Rayappan, K. Marimuthu, J. Phys. Chem. Solids 74, 1570 (2013).

[28] G. Lakshminarayana, R. Vidya Sagar, S. Buddhudu, J. Lumin. 128, 690 (2008).

[29] Xia Haiping, Zhang Jianli, Wang Jinhao, Zhang Yuepin, J. Rare Earths 24, 408 (2006).

[30] She-Bao Lin, Peng-Fei Wang, Jiang-Bo She, Hai-Tao Guo, Shen-Nuo Xu, Peng-Fei Zhao, Cheng-Long Yu, Chun-Xiao Liu, Bo Peng, J. Lumin. 153, 29 (2014).

[31] J.S. Hayden, Int. J. Appl. Glass Sci. 6, 19 (2015).

[32] A. Meijerink, G. Blasse, J. Sytsma, C. De Mello Donega, A. Ellens, Acta Phys. Pol. A 90, 109 (1996).

[33] M.H. Shaaban, Y.S. Rammah, E.M. Ahmed, A.A. Ali, J. Mater. Sci. Mater. Electron. 32, 18951 (2021).

[34] İ. Kabalci, Key Eng. Mater. 744, 387 (2017).

[35] S.H.A. Aziz, R. El-Malawany, S.S. Badaron, H.M. Kamari, K.A. Matori, Adv. Mater. Sci. Eng. 2015, 628954 (2015).

[36] A.S. Abouhaswa, E. Kavaz, J. Non-Cryst. Solids 535, 119993 (2020).

[37] M. Abdel-Baki, F. El-Diasty, J. Solid State Chem. 184, 2762 (2011).

[38] J.N. Ayuni, M.K. Halimah, Z.A. Talib, H.A.A. Sidek, W.M. Daud, A.W. Zaidan, A.M. Khamirul, IOP Conf. Series Mater. Sci. Eng. 17, 1 (2011).

[39] M.S. Gaafar, N.S. Abd El-Aal, O.W. Gerges, G. El-Amir, J. Alloys Comp. 475, 535 (2009).

[40] K. Selvaraju, K. Marimuthu, J. Lumin. 132, 1171 (2012).

[41] I. Arul Rayappan, K. Marimuthu, J. NonCryst. Solids 367, 43 (2013).

[42] P. Chen, S. Li, W. Qiao, Y. Li, Glass Phys. Chem. 37, 29 (2011).

[43] P.G. Pavani, R.V. Kumar, V.C. Mouli, Phys. Chem. Glasses Eur. J. Glass Sci. Technol. B 57, 104 (2016).

[44] E.A. Davis, N.F. Mott, Philos. Mag. 22 , 0903 (1970).

[45] N.F. Mott, E.A. Davis, Electronic Process in Non-Crystalline Materials, 2nd ed., Clarendon Press, Oxford 1979.

[46] S.P. Singh, R.P.S. Chakradhar, J.L. Rao, B. Karmakar, J. Alloys Compd. 493, 256 (2010). 